\title{
Tsunami hazard and buildings vulnerability along the Northern Atlantic coast of Morocco -the 1755-like tsunami in Asilah test-site
}

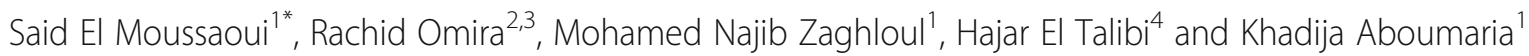

\begin{abstract}
Background: The Atlantic Coast of Morocco is prone to tsunami inundation. Therefore, in this region, earthquakeinduced tsunami hazard has been intensively investigated leading to the development of a number of coastal inundation models. However, tsunami vulnerability remains not well understood to the same extent as the hazard. In this study, we use high-resolution numerical modeling, detailed field survey and GIS-based multi-criteria analysis to assess the building tsunami vulnerability and its sensitivity to the tide variations. Asilah located in the northwestern Atlantic coast of Morocco, where the impact from the 1755 tsunami is well documented, constitutes the area of this study.
\end{abstract}

Results: To model the source-to-coast tsunami processes we used the COMCOT (Cornell Multi-grid Coupled Tsunami Model) numerical code on a set of bathymetric/topographic grid layers (640 m, $160 \mathrm{~m}, 40 \mathrm{~m}$ and $10 \mathrm{~m}$ resolutions) with an initial sea-surface perturbation generated using Okada's formulae and assuming an instantaneous seabed displacement. The tsunami source models in this study correspond to four 1755-like earthquake scenarios. Results show that Asilah's built environment is highly vulnerable to the tsunami impact that can range from 1.99 to $2.46 \mathrm{~km}^{2}$ of inundation area, depending on the source and the tidal level considered. The level of building vulnerability decreases considerably when moving away from Asilah's coastline. Moreover, the variation in the tidal level introduces large change in the modeled tsunami impact and, therefore, affects the level of building vulnerability.

Conclusion: Thus, we suggest considering the effect of the tide when simulating tsunami hazard and vulnerability, particularly, in coasts where tidal variations are significant. This study provides hazard and vulnerability maps that can be useful to develop the tsunami awareness of the Moroccan coastal population.

Keywords: Tsunami, Numerical modeling, Inundation, Vulnerability, Tide effect, Morocco

\section{Background}

The study and the understanding of coastal hazards are a fundamental aspect of most modern societies. Extreme hazard events, such as tsunamis, even though rare, are being considered as major threats to coastal regions. Moreover, as a direct consequence to the increasing occupation of coastal areas, the cost related to natural hazard has been dramatically increased (Adger et al. 2005). On the other hand, the population is still lack the

\footnotetext{
* Correspondence: said.elmoussaoui@gmail.com

${ }^{1}$ Faculty of Sciences and Techniques, University Abdelmalek Essaadi, Tangier, Morocco

Full list of author information is available at the end of the article
}

awareness regarding such events until they happen. Tsunami waves are generally devastating as they cause significant damage to both off- and on-shore goods, high erosion of beaches and even, in some cases, catastrophic loss of human life. The Northern Atlantic shore of Africa may not account among the most hazardous coasts because tsunamis are rare in the region. However, tsunami remains a real threat along the Moroccan coast as testified by historical events such as the November 1st 1775 tsunami (El Mrabet 1991; Baptista et al. 1998; Nevio Zitellini et al. 2001; Marc-André Gutscher 2004; Kaabouben et al. 2009; L. M. Matias et al. 2013). 
A detailed analysis of historical collections and archives of the 1755 tsunami has been achieved by numerous researchers (Blanc 2008; Baptista and Miranda 2009; Blanc 2009; Kaabouben et al. 2009). These analyses demonstrated that the northwest tip of the Atlantic coast of Morocco is prone to tsunami impact from the earthquake sources located in the SWIM region (Blanc 2008; Blanc 2009; Kaabouben et al. 2009). The historical records mention an extreme impact of the 1755 tsunami on the city of Asilah, with waves surging the fortifications, which suggest a run-up of at least $15 \mathrm{~m}$. They also describe waves penetrating up to $2 \mathrm{~km}$ inland. However, Omira et al. (2012), using tsunami numerical simulations, show that at some locations along the coast of Morocco the historical reports may overestimated the tsunami impact.

The November 1st 1755 earthquake and tsunami remain the largest natural disaster in the South West Iberian Margin (SWIM) for the last 500 years, in terms of loss of lives and destruction (Baptista and Miranda 2009; Kaabouben et al. 2009). It is also one of the only destructive events described in detail by historical documents in this area (El Mrabet 2005; Kaabouben et al. 2009). The shaking of the 1755 earthquake was felt all over the Iberian Peninsula, Morocco, and as far as Hamburg, the Azores and Cape Verde Islands (Martínez Solares et al. 1979). Recent evaluation of the earthquake magnitude proposes an $\mathrm{Mw}=8.5 \pm 0.3$ (Martínez Solares and Arroyo 2004). The tsunami waves caused massive destruction in the southwest Iberian Peninsula and Northwest Morocco (Baptista et al. 1998; El Mrabet 2005; Kaabouben et al. 2009). Historical documents, mainly the manuscript of Soyris (1755), described in details the waves along the coasts of Morocco, Portugal and Spain, mentioning tsunami run-ups as high as $15 \mathrm{~m}$ and wave height of $24 \mathrm{~m}$ in some locations (Blanc 2008; Kaabouben et al. 2009).

Although the 1755 tsunami has been studied in detail (El Mrabet 2005; Blanc 2008; Mhammdi et al. 2008; Baptista and Miranda 2009; Blanc 2009; Kaabouben et al. 2009; Medina et al. 2011; El Talibi et al. 2016), the very low frequency of such events limits tsunami hazard assessment and countermeasure preparations.

The Tangier-Asilah region (northwest Morocco, see Fig. 1 for location) has an increasingly growing population especially towards its coast (RGPH 2014). The tectonic context and the historical data both suggest a high

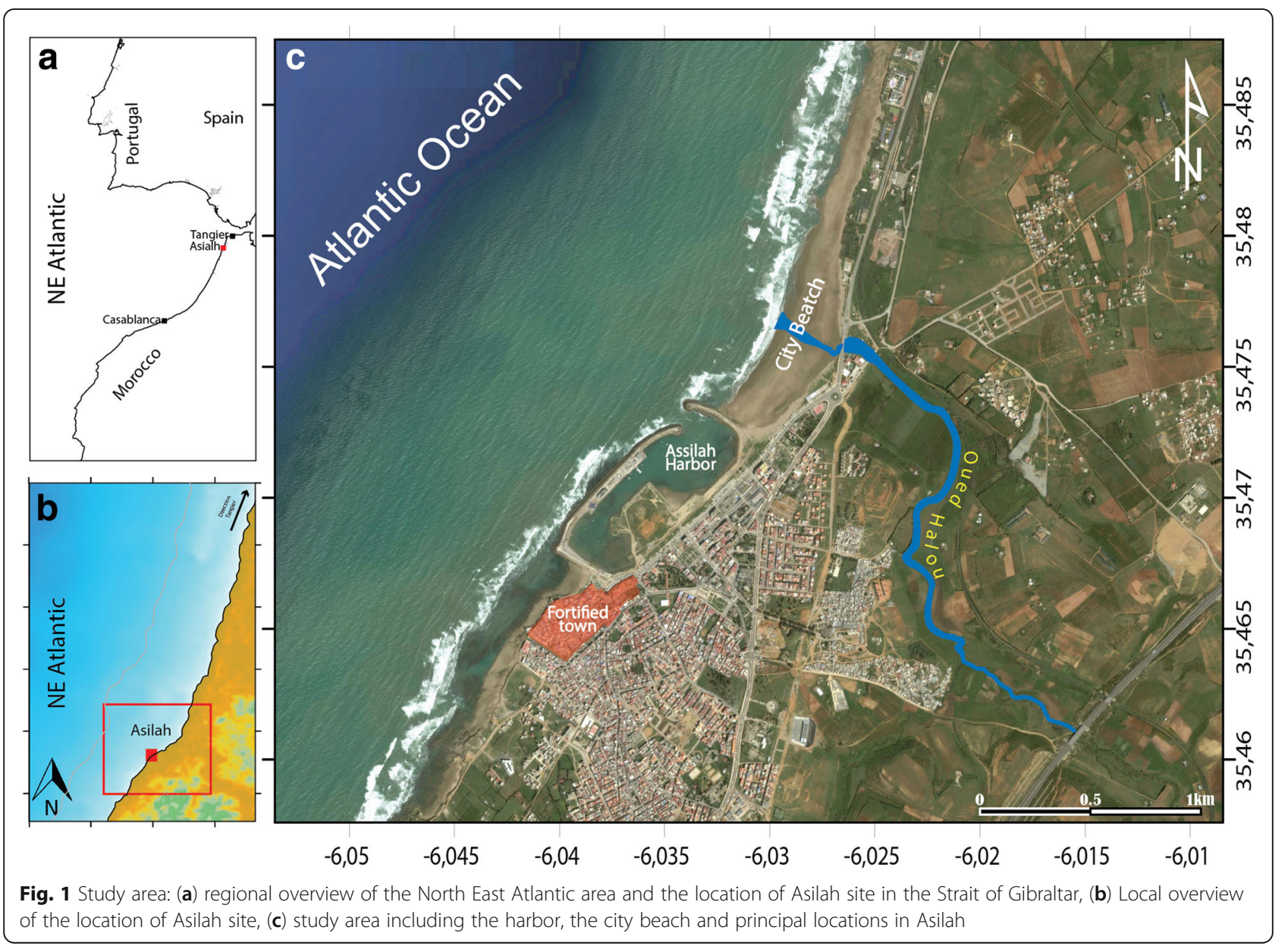


susceptibility of the region to tsunami hazard (Cherkaoui and El Hassani 2012). Therefore, a robust strategy to mitigate the consequences of a future tsunami impact on the infrastructure in this area is strongly required. Risk assessment plays an important role in designing strategies for disaster risk reduction and response. Hazard and vulnerability are the main components of any comprehensive risk assessment. For the tsunami phenomenon, the hazard assessment along a threatened coast is often covered by numerical modeling of the resulting inundations through the deterministic method (Tinti and Armigliato 2003; Tinti et al. 2005; Løvholt et al. 2006; Baptista et al. 2011; Omira et al. 2011; Omira et al. 2013) or the probabilistic analysis (González et al. 2009; Omira et al. 2016). In addition, vulnerability study is trans-disciplinary and multi-dimensional, covering social, economic, physical, political, engineering and ecological aspects and dimensions (Post et al. 2009).

In the aftermath of the Indian Ocean 2004 tsunami, efforts have been made to develop vulnerability assessment models for different types of exposure (Dominey-Howes and Papathoma 2007; Omira et al. 2010). Most works address the vulnerability of buildings using empirical fragility functions and damage curves. Data collected during post-tsunami field surveys were crucial to establish the relationship between the observed damage level and tsunami flow depth and/or current velocity (Reese et al. 2007; Dias et al. 2009; Leone et al. 2011; Suppasri et al. 2012; Suppasri et al. 2013). Furthermore, Valencia et al. (2011) developed, in the framework of SCHEMA (SCenarios for Hazard-induced Emergencies MAnagement) EU project (FP6, no. 030963), a new approach to assess tsunami vulnerability through deriving fragility functions and damage curves for the European-Mediterranean coastal buildings. This methodology was applied to assess the expected buildings tsunami damage in the SCHEMA test-sites (Atillah et al. 2011; Renou et al. 2011; Valencia et al. 2011). Alternative GIS-multi-criteria-based methods were also proposed to qualitatively estimate the expected tsunami damage and the corresponding vulnerability level for coastal buildings under tsunami impact (Papathoma et al. 2003; Omira et al. 2010).

From source to coast, tsunami waves can be affected by several factors, observations have shown that tsunamis form long wave trains that persist over several tidal cycles (Miller et al. 1962; Van Dorn 1984; Van Dorn 1987; Mofjeld et al. 2000; Mofjeld et al. 2007). Weisz and Winter (2005) affirms that theoretically tidal variation can influence the speed and magnitude of tsunami waves in shallow regions. Furthermore, numerical experiments have illustrated that the nonlinear interaction between tides and tsunamis in shallow water becomes very significant, while the linear superposition of sea surface heights from separate tide and tsunami simulations is still valid in deep water (Kowalik et al. 2006; Androsov et al. 2010). Another conclusion, based on previous idealized and regional studies, was drew by Kowalik and Proshutinsky (2010), stating that the nonlinear interactions between tsunami and tide is the main cause of the changing conditions of tsunami propagation and run-up. Kalmbacher and Hill (2015), using numerical simulations on the Columbia River, also conclude that tsunami wave heights increase with decreasing tidal level.

In this paper, we aim at investigate tsunami impact and vulnerability in the bay of Asilah -Morocco (Fig. 1) while evaluating their sensibility to the effect of the tidal variation. This is achieved by: i) performing highresolution inundation modeling using the scenario-based approach described in Tinti and Armigliato (2003) and other recent applications along the Moroccan coastline (Omira et al. 2010; Omira et al. 2011; Omira et al. 2013; Benchekroun et al. 2015; Wronna et al. 2015), and ii) investigating the building vulnerability using an approach based on a combination of the results of tsunami hydrodynamic modeling, information collected during the building inventory and the use of GIS tools allowing multicriteria analysis and vulnerability mapping. This building vulnerability assessment method is based on the BTV model proposed by Omira et al. (2010). Furthermore, we discuss the effect of the tide variation on the tsunami hazard and vulnerability along the coast of Asilah.

\section{Study area and regional settings}

Asilah city is located on the northwest tip of the Atlantic coast of Morocco, about $31 \mathrm{~km}$ south of Tangier (Fig. 1). According to the Moroccan General Population and Housing Census of 2014, the city records a population of 31,014 inhabitants; with a number increasing drastically during summer season (RGPH 2014). In this study, the Asilah coast, the harbor zone, and the fortified town are considered (Fig. 1). The Asilah site is selected to study the tsunami vulnerability of the building stock along the Moroccan coast, for a number of reasons, including: i) Asilah was heavily mentioned in the historical reports related to the impact of the November 1st 1755 tsunami (El Mrabet 2005; Blanc 2008; Blanc 2009; Kaabouben et al. 2009), ii) the presence of a large variety of buildings types within the coastal zone prone to tsunami inundation, iii) the high seasonal population dynamics, daily average of 75,000 persons (DPDRSP 2004), and iv) the presence of a major harbor and a large residential and touristic complex along the coast. Moreover, the study area of Asilah is characterized by a low surface elevation (between 0 and $78 \mathrm{~m}$ ) with gentle slopes, increasing its susceptibility to tsunami inundation.

The choice of Asilah is also justified by its geological context and proximity to the Nubia-Eurasia plate boundary (NEPB). In fact, several possible tsunami 
sources are identified along the Gulf of Cadiz (Johnston 1996; N. Zitellini et al. 1999; M.-A. Gutscher et al. 2002; L. Matias et al. 2005; M. -A. Gutscher et al. 2006; M. -A. Gutscher et al. 2006). The dextral transform zone of the Azores-Gibraltar is one of the most tectonically active zones in the Atlantic Ocean that has historically experienced a number of large earthquake induced tsunamis (El Alami and Tinti 1991; Baptista et al. 1998), particularly the 1755 November 1st (M. -A. Gutscher et al. 2006). This area is still active, as evidenced by the earthquake of February 28th 1969 (Mb 7.9) and of February 12th 2007 (Mb 6.3), also felt in Morocco.

\section{Methodology \\ Innundatin modeling}

To assess the tsunami hazard at Asilah site, we use the scenario-based approach that consists of determining the impact at a selected coastal area from specific tsunami events using numerical modeling. We test all the Maximum Credible Earthquake Scenarios (MCES), for which we use the typical faults (TFs) presented in Omira et al. (2009). Then, to achieve the final step of hazard assessment, we build the aggregate-scenario that triggers the higher tsunami impact (in terms of inundation extent and run-up) in each cell considering the contribution of the individual scenarios along the coastal strip of Asilah (Tinti et al. 2011).

In this study, we select four TFs in the SWIM region; all are source candidates of the November 1st 1755 earthquake. They correspond to the Gorringe Bank fault (GBF) (Johnston 1996), the Marques de Pombal Fault (MPF) (N. Zitellini et al. 1999), the Horseshoe Fault (HSF) (Gràcia et al. 2003; L. Matias et al. 2005), and the Cadiz Wedge Fault (CWF) (M.-A. Gutscher et al. 2002; M. -A. Gutscher et al. 2006) (See Fig. 2a for location). Table 1 depicts the TF parameters used to model the generation of the tsunami that follows the earthquake.

Tsunami propagation and run-up calculations are performed using the open source COMCOT code (Cornell Multi-grid Coupled Tsunami Model) that solves both linear and non-linear shallow water equations in spherical or Cartesian coordinates using an explicit leap-frog finite difference numerical scheme (Liu et al. 1998). The code also allows employing a nested grid system with increasing grid resolutions in order to fulfil the need for tsunami simulations at different scales from the source zone to the high resolution target coast where inundation maps are computed (Wang 2009). COMCOT code has been used to study several tsunami events such as the 1755 Lisbon tsunami (Baptista et al. 2011; Omira et al. 2011; Omira et al. 2013), the 2003 Algeria tsunami (Wang and Liu 2005) and, more recently, the 2004 Indian Ocean tsunami (Wang and Liu 2006).

A set of bathymetric/topographic nested grids was generated in order to cover the areas from the source zone to the target coast (Fig. 2). These digital elevation models (DEMs) were produced to meet the following criteria: i) homogeneous mapping with increasing resolution from the tsunami source area to the test site coast, ii) high horizontal resolution in the test-site in order to ensure a better representation of the coastal bathemetric/topographic features, and iii) continuity offshore-onshore in respect to the vertical datum. The bathymetric/topographic grid layers were generated from a compilation of multisource height/depth data that includes: the GEBCO 30 Arc-second grid as a starting point, and the compilation of nautical maps of the Moroccan margin. The topographic grid of approximately $30 \mathrm{~m}$ resolution form (ASTER-GDEM V2), encompassing the sources area offshore the Moroccan margin, extends from $38^{\circ} \mathrm{N}$ to $83^{\circ} \mathrm{S}$, was also used to build the DEM. A set of grid layers $(640 \mathrm{~m}, 160 \mathrm{~m}, 40 \mathrm{~m}$ and $10 \mathrm{~m}$ resolutions) are nested for consecutive calculations of tsunami generation, propagation in an open boundary condition and inland inundation.

The main grid, $640 \mathrm{~m}$-resolution, is the same that was used in the previous tsunami simulation works (Benchekroun et al., 2015) (Fig. 2a). The second and the third grid levels (Fig. 2b, c) were obtained by interpolating the main grid to $160 \mathrm{~m}$ and $40 \mathrm{~m}$. The local grid, a 10 m-resolution DEM (Fig. 2d), was compiled from different sources of altimetry and depth data. The bathymetric charts were referenced to the mean sea level, merged on a unique database, and all data was transformed to WGS84/UTM coordinates. The coastline has been corrected using recent satellite imagery.

To account for the tidal effects on tsunami impact and vulnerability we simulate the waves' propagation for three static tide stages: mean lower low water (MLLW), mean sea level (MSL), and mean higher high water (MHHW). The values of MLLW and MHHW with respect to the MSL, corresponding to $-0.77 \mathrm{~m}$ and $1.17 \mathrm{~m}$, respectively, were obtained from 2-years (2014-2015) time-series records of the Larache harbor tide-gauge (DPDPM 2014; DPDPM 2015).

\section{Building tsunami vulnerability}

In this study, we applied the building tsunami vulnerability (BTV) model proposed by Omira et al. (2010) in which, the authors distinguish between the "main criteria" and the "intrinsic attributes" that influence the vulnerability of coastal buildings to tsunamis. The main criteria, which are defined and weighted independently of the test-site, consist of: 1) building resistance condition, 2) inundation zone hazard and 3) sea-defense resistance condition (Omira et al. 2010) (Fig. 3). Additionally, the BTV model requires a field survey to define vulnerability classes within the criteria 1 and 3 , and 


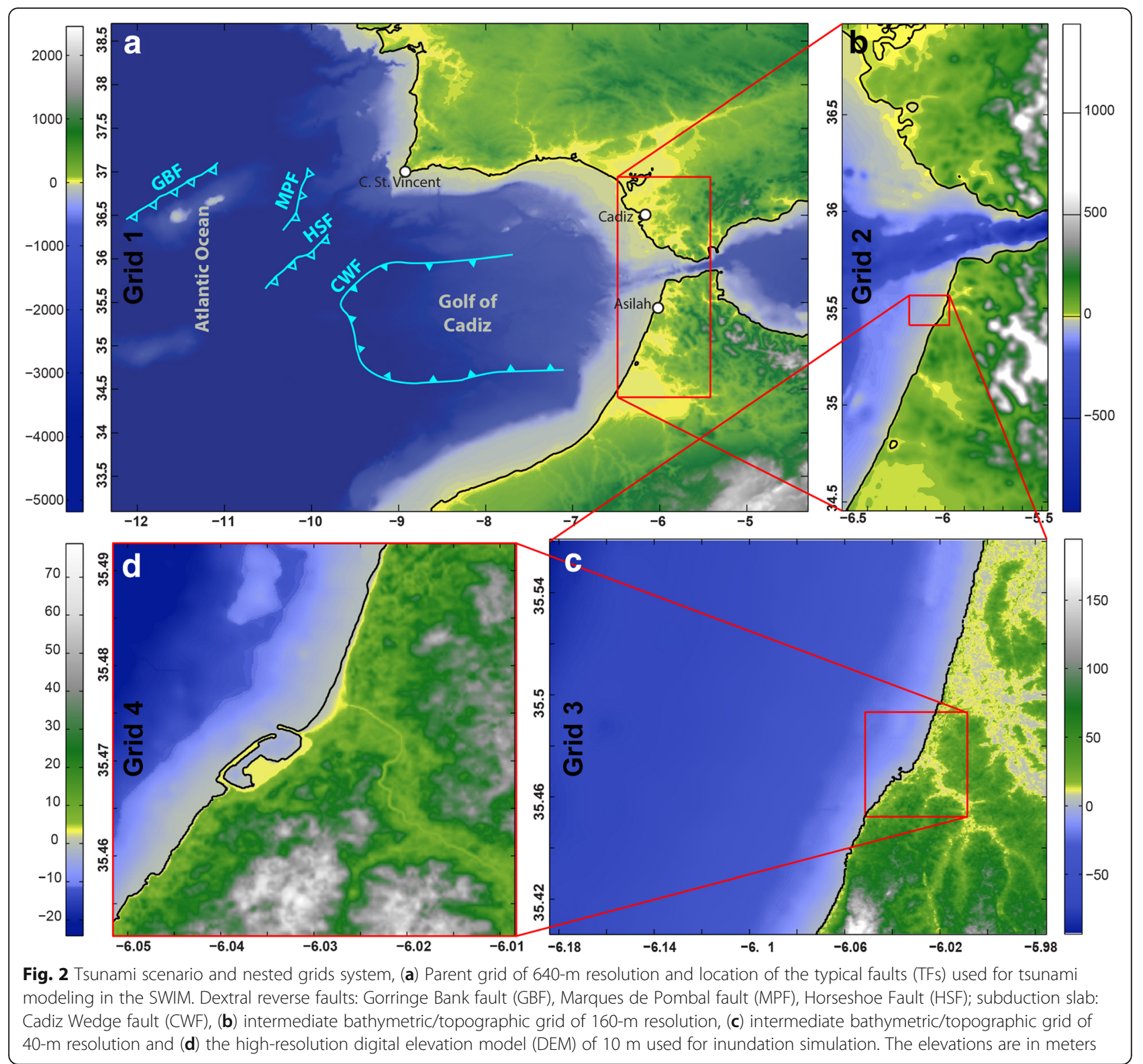

numerical modeling for inundation hazard classes (criterion (2)).

The field survey covered the building stock and seadefense structures within the study area with the objective to characterize the elements controlling the vulnerability and therefore deriving the classification factors. This led to establish building and sea defense classes (Fig. 3) and their corresponding classification factors (Table 2). Identified building types were grouped into four classes ranging from buildings with very good resistance (class A) to buildings with very weak resistance (class D) (see Fig. 3). The field survey also revealed areas that are relatively well

Table 1 Fault parameters of the tsunamigenic sources considered in this study. These parameters have been used for the three different tides MHHW, MSL, and MLLW

\begin{tabular}{|c|c|c|c|c|c|c|c|c|c|}
\hline Fault & $\mathrm{L}(\mathrm{km})$ & $W(\mathrm{~km})$ & Rake $\left(^{\circ}\right)$ & Strike $\left({ }^{\circ}\right)$ & $\operatorname{Dip}\left({ }^{\circ}\right)$ & Slip (m) & Depth (km) & $\mu\left(10^{10} \mathrm{~Pa}\right)$ & $M_{w}$ \\
\hline $\mathrm{HSF}$ & 165 & 70 & 90 & 42.1 & 35 & 15 & 5 & 4.5 & 8.5 \\
\hline MPF & 110 & 70 & 90 & 20.1 & 35 & 8 & 5 & 4.5 & 8.25 \\
\hline CWF & 170 & 200 & 90 & 349 & 5 & 10 & 5 & $3.0_{-}$ & 8.64 \\
\hline GBF & 200 & 80 & 90 & 53 & 35 & 10 & 5 & 4.5 & 8.5 \\
\hline
\end{tabular}



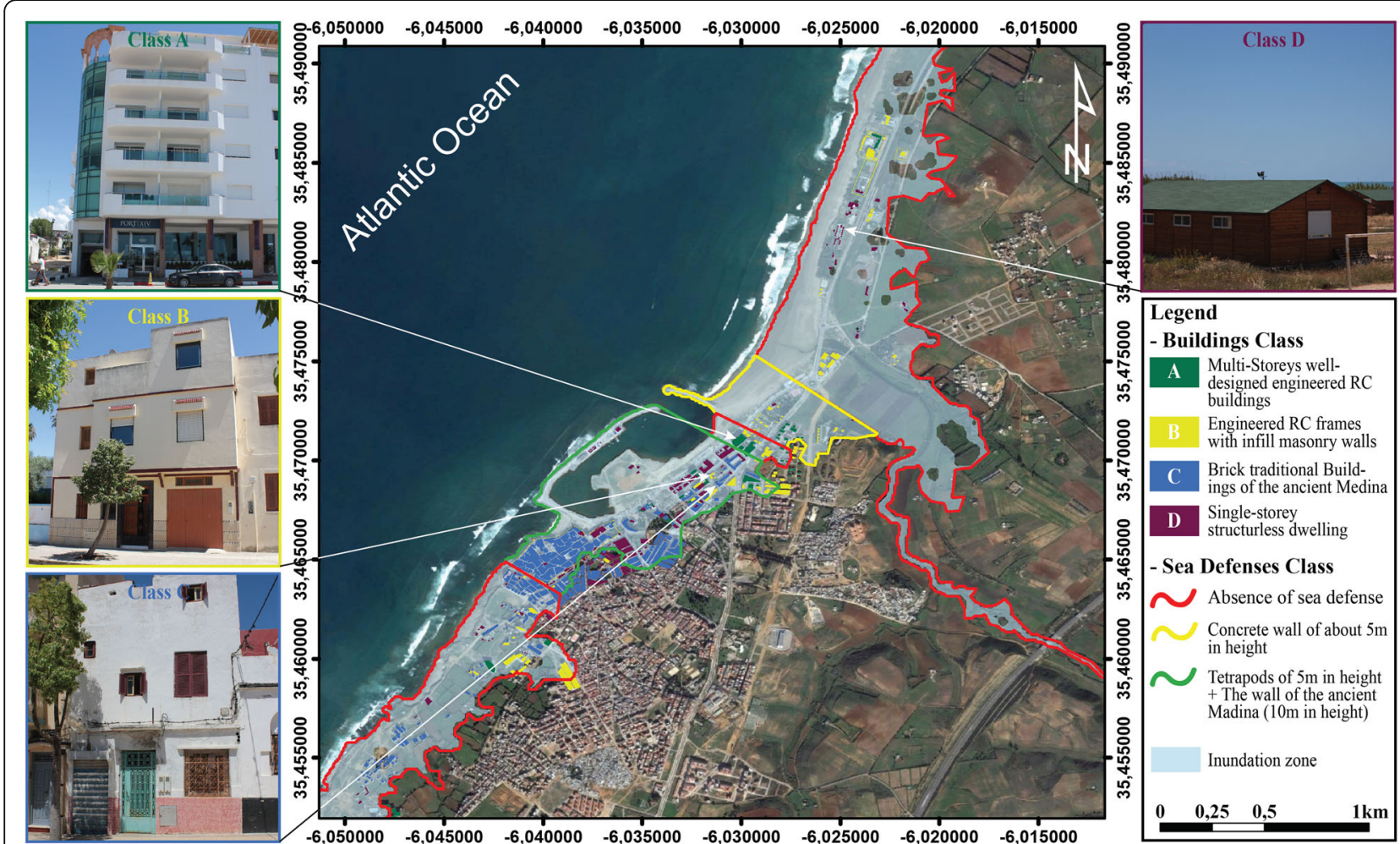

Fig. 3 Map displaying buildings classes (A: multi-storeys well-designed engineered RC buildings, B: non-engineered RC building with masonry infill walls, C: non-engineered timber construction, brick traditional buildings of the Old Town, D: Single-storey structureless dwelling), and sea-defense classes identified during the field survey in Asilah-Morocco

protected from tsunami waves, areas where protection is moderate, and areas where there is almost no defense against the sea waves. The protective structures identified along Asilah coast consist of 3 types with various construction materials and dimensions (Fig. 3). We found: i) Rubble mound breakwater armored by concrete Tetrapods with a concrete sea wall of about $5 \mathrm{~m}$ height and $1 \mathrm{~m}$ thickness (the structure that protects the city harbor), ii) the wall of the Old town of about $10 \mathrm{~m}$ height and $1 \mathrm{~m}$ to $2 \mathrm{~m}$ thickness, and ii) a concrete retaining wall extending from the north of the harbor to the northern entrance of the town, $5 \mathrm{~m}$ high and $0.6 \mathrm{~m}$ of thickness. Identified defense structures were grouped into three classes (Table 2) according to their capacity of resistance to an eventual tsunami impact (cf. Fig. 3). The classification of zones prone to tsunami flooding is based on the results of tsunami inundation modeling performed in Section 4.1. The classification of flooded area requires the identification of sub-zones presenting different inundation risk levels. Here, four tsunami inundation classes are considered within the flooded area. This classification is based on the number of floors flooded (Table 2).

The method used to investigate the vulnerability of buildings to tsunami requires a multi-criteria analysis, that control the tsunami buildings damage. The dynamic aspect of vulnerability is taken into account by introducing the weighting and classification factors (Table 2) in a dynamic formula (Omira et al. 2010).

Table 2 Criteria considered to control the tsunami buildings vulnerability, their corresponding weight factors $\left(F_{\mathrm{w} . \mathrm{i}}\right)$ and classification factors ( $F_{c . b}$ for building condition, $F_{c . i}$ for inundation zone, and $F_{c . s}$ for sea defense)

\begin{tabular}{|c|c|c|c|c|c|c|}
\hline \multirow{3}{*}{$\begin{array}{l}\text { Weight Factor }\left(F_{\text {w.i. }}\right) \\
\text { Class }\end{array}$} & \multicolumn{2}{|l|}{ Building } & \multicolumn{2}{|l|}{ Inundation zone } & \multicolumn{2}{|l|}{ Sea defense } \\
\hline & \multicolumn{2}{|l|}{3} & \multicolumn{2}{|l|}{2} & \multicolumn{2}{|l|}{1} \\
\hline & Condition level & $F_{c . b}$ & Corresponding Flow depth (m) & $F_{c . i}$ & Resistance level & $\mathrm{F}_{c .5}$ \\
\hline A & Very good & 1 & $0-4$ & 1 & Good & 1 \\
\hline B & Good & 2 & $4-8$ & 2 & Medium & 2 \\
\hline C & Medium & 3 & $8-12$ & 3 & Bad & 3 \\
\hline D & Bad & 4 & $>12$ & 4 & - & - \\
\hline
\end{tabular}




\section{Results}

Tsunami inundation

A total of 12 simulations were run considering four earthquake scenarios and three tide conditions (MLLW, MSL and MHHW). Initial wave heights of $5.6 \mathrm{~m}, 5.8 \mathrm{~m}$, $5.5 \mathrm{~m}$ and $4.7 \mathrm{~m}$ were produced following the HSF, the CWF, the GBF, and the MPF scenario, respectively. The CWF scenario led to the highest wave at the shore, with a maximum height of $25.83 \mathrm{~m}$. In Fig. 4, we present results of tsunami inundation modeling, including flood extent and area and flow depth, for each individual 1755-like scenario, calculated for the mean sea level (MSL) condition. These results clearly show that the CWF scenario causes the worst tsunami impact over the coastal area of Asilah. This scenario produces a maximum wave height $(\mathrm{MWH})$ of about $25 \mathrm{~m}$. The inland inundation distance reaches $1.16 \mathrm{~km}$ in Asilah harbor and surrounding area and extends even more along the Halou river (see Fig. 4). The maximum flow depth (MFD) is about $22.8 \mathrm{~m}$ with the maximum inundation values over the sandy beach especially in the river mouths and main lagoon areas. A detailed analysis indicates flow depths larger than $0.5 \mathrm{~m}$ in $87 \%$ of the inundation area. The maximum inundated area (MIA) is about $2.16 \mathrm{~km} 2$.

In comparison with CWF, the HSF scenario produces less tsunami impact (Fig. 4a). In this case, the MWH and MFD reach values of $11.5 \mathrm{~m}$ and $11 \mathrm{~m}$, respectively. The inundation extent is limited to the beach and the riverbed, with a maximum value of $0.24 \mathrm{~km}$. The flooded area is about $0.6 \mathrm{~km}^{2}$. On the other hand, the MPF scenario (Fig. 4d) presents similar tsunami hazard as the HSF, but with a slightly reduced inundation area, MIA of about $0.42 \mathrm{~km}^{2}$. Also, the MPF scenario leads to lower wave heights of about $6.8 \mathrm{~m}$ close to the coast, and MFD and MIE reaching $6.2 \mathrm{~m}$, and $0.23 \mathrm{~km}$, respectively. Within the SWIM region, the GBF scenario (Fig. 4d) produces the weakest tsunami impact in Asilah, MIA of $0.24 \mathrm{~km}^{2}$, MWH of $6.4 \mathrm{~m}$ and MFD of $5 \mathrm{~m}$. The inundation from this scenario is limited to the beach zone, and did not penetrate the riverbed as observed for the other scenarios.

Considering the tsunami impact from all the studied scenarios, we generate an aggregate scenario map that represents the extreme hazard values field by taking the contribution of all individual scenarios (Fig. 5). The result clearly shows the dominance of the CWF scenario. In the Table 3 , we summarize the numerical modeling results (MWH, MFD, MIE, and MIA) for all the considered scenarios and for different tidal conditions, including MLLW, MSL, and MHHW.

\section{Building vulnerability map}

The results of BTV assessment are represented in the form of a vulnerability map (Fig. 6). Tsunami vulnerability levels range from low, corresponding to slight no structural damage, to very high, corresponding to a total destruction (Fig. 6). Analysis of the BTV results, clearly indicates that most buildings, about $51.6 \%$, have medium damage level (slight structural damage) (Fig. 7).These buildings belong to the class $\mathrm{C}$ (Table 2) and are located within an area of medium flow depth but well protected by the wall of the Old town and the harbor breakwaters (see Fig. 3).

Buildings with high vulnerability level (severe structural damage) represent $32.84 \%$ of the flooded coastal structures of Asilah (Fig. 7). These buildings mainly belong to classes $\mathrm{B}$ and $\mathrm{C}$. Their location within a height inundated area $(8 \mathrm{~m}<\mathrm{MFD}<12 \mathrm{~m})$, in addition to the absence of the sea defense structures in front of them, lead to increase their vulnerability to tsunami damage.

The BTV for class D ranges from high to very high vulnerability level (severe structural damage to total destruction) and represents $8.74 \%$ of the built-up area (Fig. 7). These buildings are located along the limit of the sandy beach and in the harbor zone. The very highly vulnerable category includes also buildings of class $\mathrm{C}$. On the other hand, buildings with low vulnerability level remains rare, they represent $6.82 \%$ of buildings (Fig. 7), and are mainly of class A located in low flooded area.

In summary, the spatial distribution of BTV in the study area (Fig. 6), shows that all buildings categories, could suffered damage at different levels in case an event similar to the 1755 tsunami hits the area.

\section{Discussion}

\section{Impact and vulnerability}

The four "1755-like" scenarios cause dissimilar tsunami inundation along the coast of Asilah. The level of impact ranges from low, corresponding to limited flood of the sandy beach, to very high when tsunami waves advance inland up to $1.16 \mathrm{~km}$. The CWF scenario appears to produce the worst tsunami impact along the Asilah coast (flooded area of more than $2 \mathrm{~km}^{2}$ ) and, therefore, largely contribute to the aggregate scenario. On the other hand, the GBF scenario produces the lowest inundation area of $0.24 \mathrm{~km}^{2}$. Among the considered scenarios, the CWF and the HSF are more efficient to radiate tsunami energy towards the northern coast of Morocco (see Omira et al. (2009) for the regional tsunami energy patterns in the Gulf of Cadiz).

The application of the BTV model leads to valuable insight on the vulnerability of the coastal buildings to the tsunami impact at Asilah-Morocco. The variety in the types of structures along Asilah coast allows estimating the damage level of different buildings categories in different inundation conditions. Within the inundation area of $2.17 \mathrm{~km}^{2}$, about $41.6 \%$ of the buildings are highly to very highly vulnerable to the tsunami from the SWIM region. 

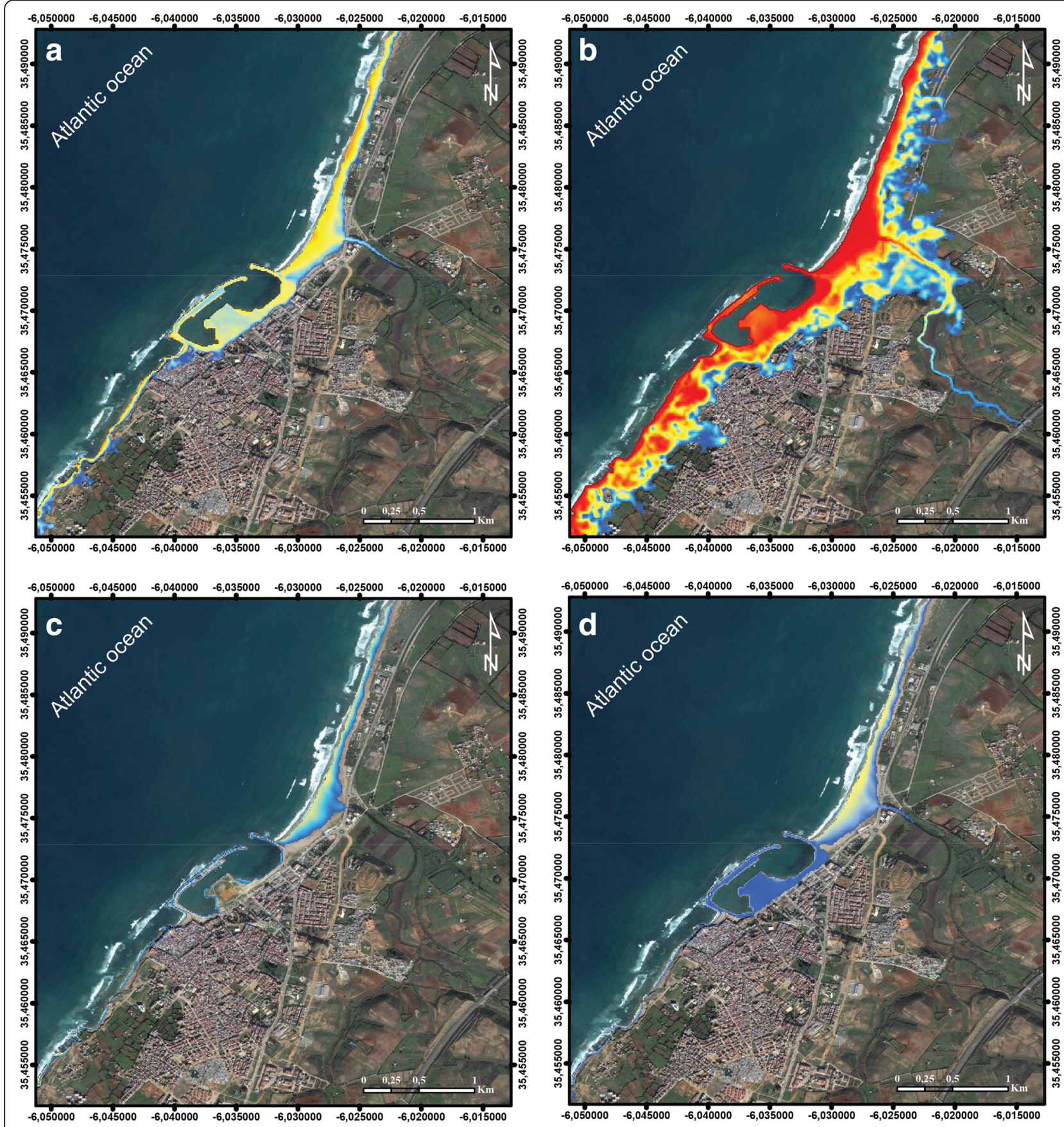

\section{Maximum Flow Depth}

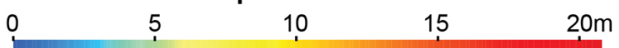

Fig. 4 Results of inundation area and maximum flow depths for each proposed source model of the November 1 st 1755 Lisbon earthquake considering MSL condition: (a) HSF; (b) CWF; (c) GBF; (d) MPF. MFD are represented by the color bar (in meters)

These results clearly demonstrate that buildings along the coast of Asilah are not designed to withstand the tsunami impact, especially with the absence of sea defense structures that can protect or, at least, reduce the tsunami effects. Structures of the Asilah's Old town belong to vulnerability class raging from medium to high. The occurrence of a tsunami similar to the 1755 event can cause major damage on these buildings of great historical and cultural importance.

Tsunami vulnerability remains less investigated in comparison to the tsunami hazard. Despite this fact, a 


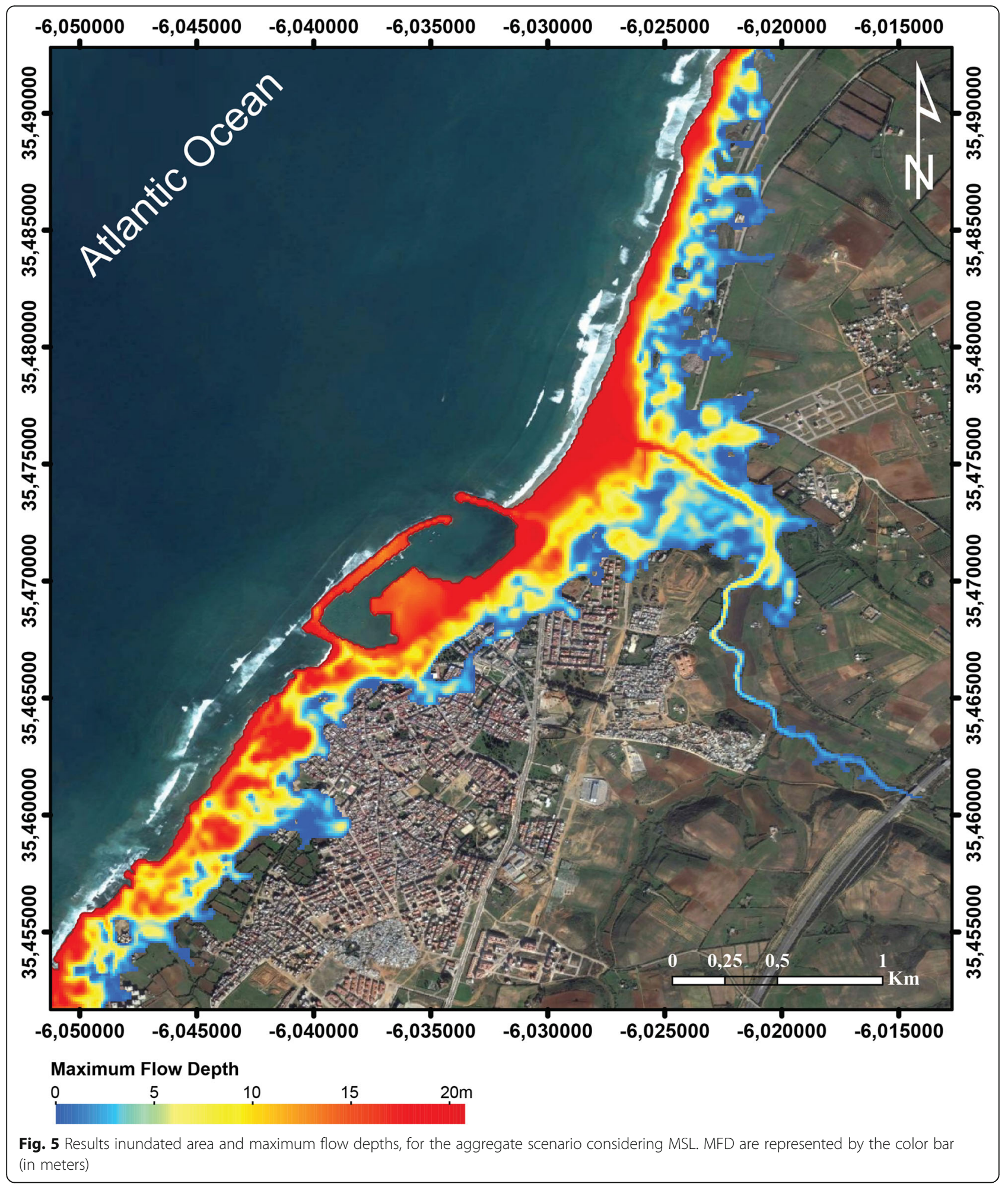

number of recent studies on tsunami vulnerability assessment have been carried along the coasts of Morocco, including the coast of Casablanca (Omira et al. 2010), Rabat-Sale (Atillah et al. 2011), and Tangier (Benchekroun et al. 2015). Although diverse vulnerability methods have been employed, these studies have led to quite comparable results. Omira et al. (2010) show that, in Casablanca, constructions with very weak structural conditions located in unprotected near-shore areas within a high inundation risk zone present very high vulnerability level. They also 
Table 3 Summary table of resulted MHW, MFD, MIE and MIA for each proposed source model of the 1st November 1755 Lisbon earthquake and the aggregate scenario considering the three tide stages

\begin{tabular}{|c|c|c|c|c|c|c|c|c|c|c|c|c|}
\hline \multirow[b]{2}{*}{ Tide Stage/Scenario } & \multicolumn{3}{|c|}{$\mathrm{MWH}(\mathrm{m})$} & \multicolumn{3}{|c|}{ MFD (m) } & \multicolumn{3}{|c|}{ MIE (km) } & \multicolumn{3}{|c|}{$\mathrm{MIA}\left(\mathrm{km}^{2}\right)$} \\
\hline & MLLW & MSL & MHHW & MLLW & MSL & MHHW & MLLW & MSL & MHHW & MLLW & MSL & $\mathrm{MHHW}$ \\
\hline$\overline{C W F}$ & 25.83 & 25.64 & 23.07 & 22.83 & 22.85 & 21.63 & 1.10 & 1.16 & 1.30 & 1.99 & 2.16 & 2.46 \\
\hline HSF & 13.23 & 11.65 & 11.87 & 9.63 & 11 & 10.71 & 0.24 & 0.24 & 0.42 & 0.56 & 0.60 & 0.71 \\
\hline MPF & 6.77 & 6.83 & 8.46 & 5.75 & 6.23 & 7.93 & 0.23 & 0.23 & 0.41 & 0.38 & 0.42 & 0.50 \\
\hline GBF & 5.76 & 6.40 & 8.8 & 4.36 & 5.5 & 8.8 & 0.22 & 0.23 & 0.24 & 0.28 & 0.24 & 0.48 \\
\hline Aggregate & 25.83 & 25.64 & 23.07 & 22.83 & 22.85 & 21.63 & 1.10 & 1.16 & 1.30 & 1.99 & 2.17 & 2.46 \\
\hline
\end{tabular}

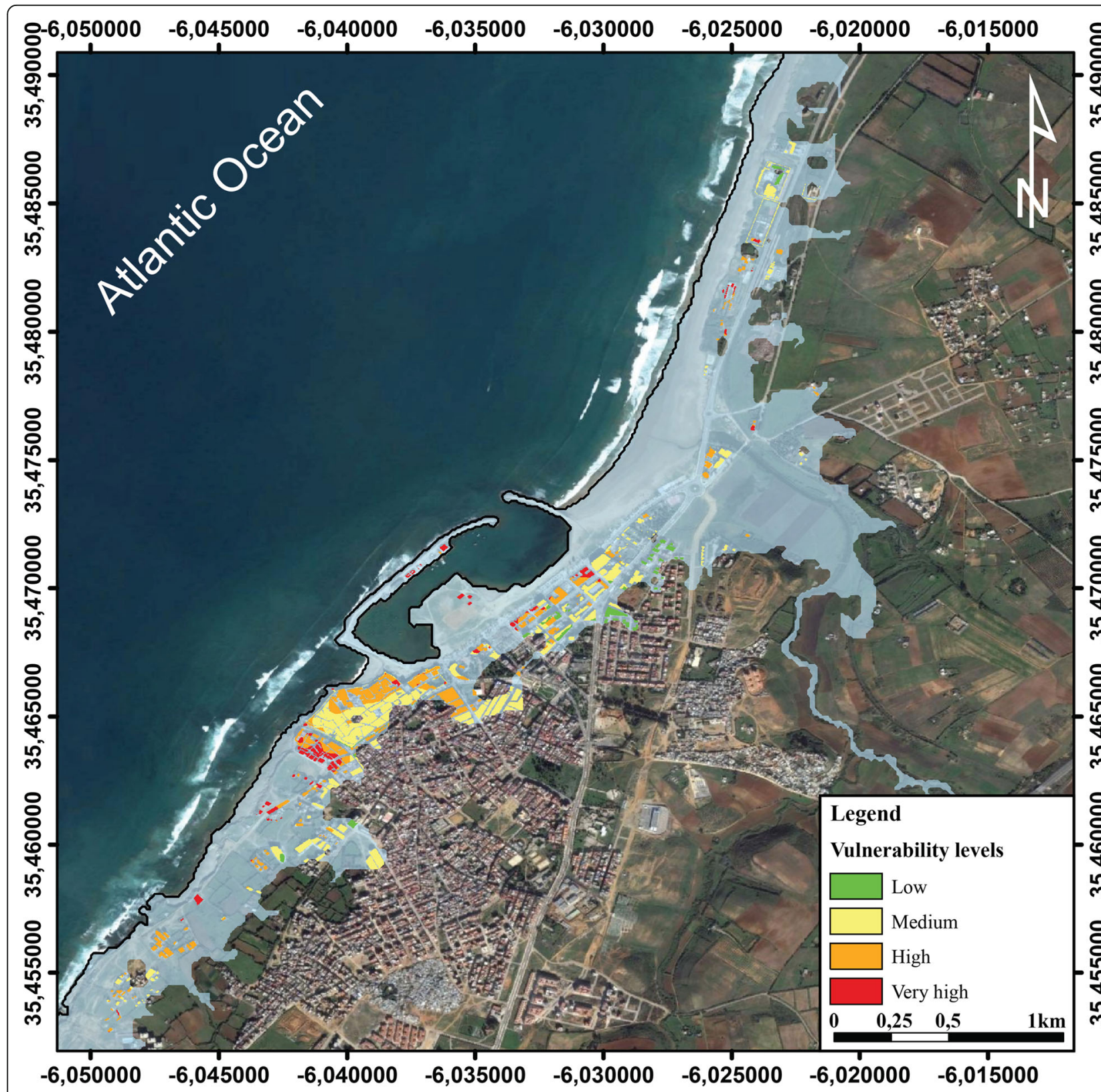

Fig. 6 Building tsunami vulnerability Map displaying the level of vulnerability caused by tsunami impact along the Asilah bay; the Low level corresponds to slight no structural damage, Medium corresponds to slight structural damage, High corresponds to severe structural damage, and Very high corresponds to a total destruction 


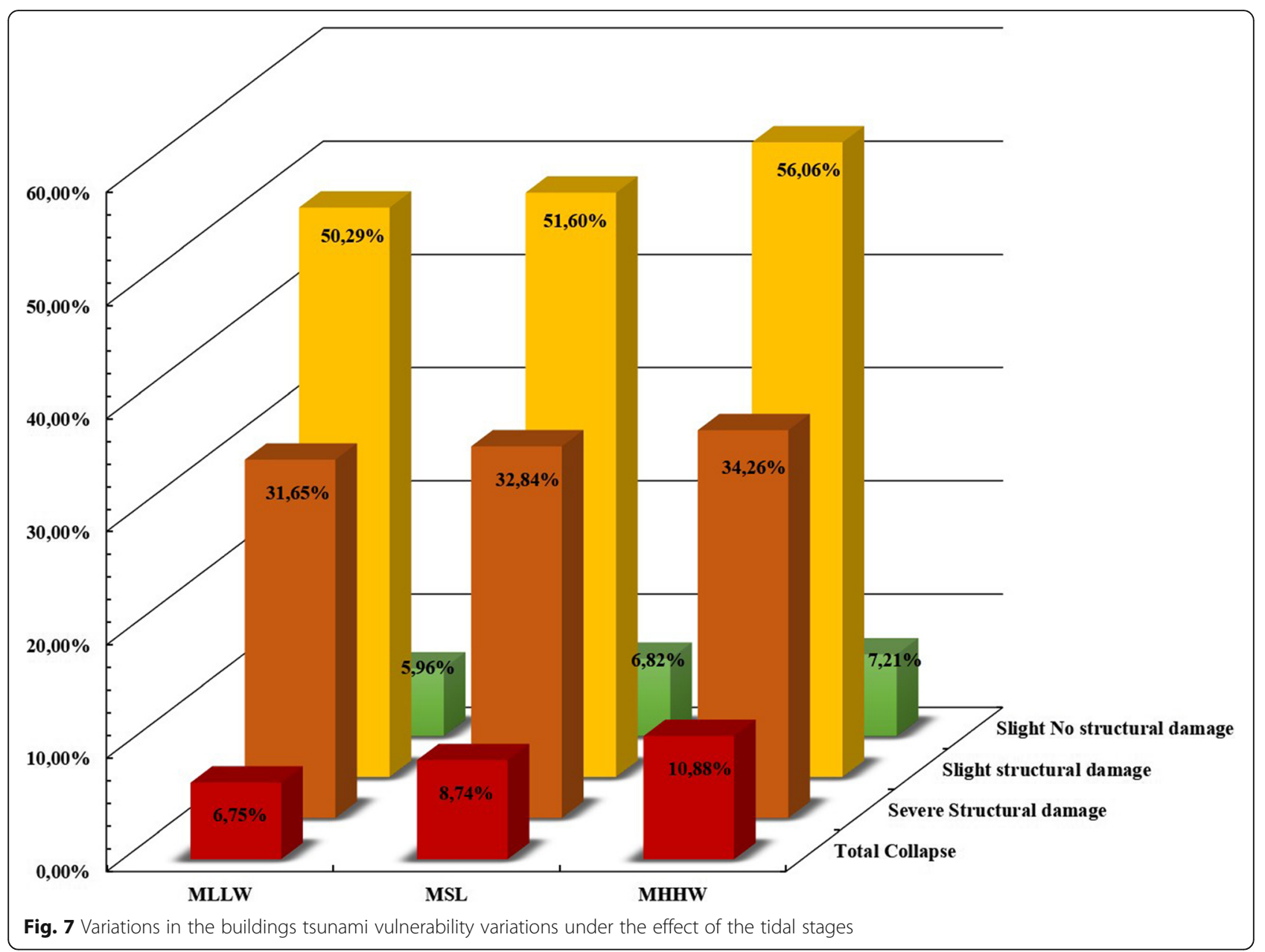

conclude that RC structures could withstand the tsunami impact (low to medium vulnerability) even in inundation zones of high flow depth. Atillah et al. (2011) study reaches comparable conclusions and expects a total destruction of the weak constructed structures facing the sea in Rabat-Sale coast. Benchekroun et al. (2015) outlined different levels of expected buildings vulnerability to tsunami impact, which vary from very high for single-storey structures, located in the Tangier city harbor and along the sandy beach, to low for multi-storeys RC structures. This study presents vulnerability results that correlate well with the findings of the previous studies (Omira et al. 2010; Atillah et al. 2011; Benchekroun et al. 2015). This includes the very high-to-high vulnerability levels attributed to the A and B building classes of very weak structural conditions and mainly located in the first line front to the sea. Also, for multi-storeys well-designed RC structures (C and D classes) medium to low vulnerability levels, depending on their locations, were attributed in all the mentioned studies. The only difference concerns vulnerability of the Old town, with structural typology widely present in the major cities of Morocco. While these structures are highly vulnerable in Casablanca (Omira et al. 2010), they are less vulnerable in Rabat (D1-D3 damages, (Atillah et al. 2011)) due to limited flow depth, and not vulnerable in Sale and Tangier as the tsunami does not reach them due to their location in high ground.

\section{Influence of tidal variation on BTV}

It is well recognized that the tide level at the time of the tsunami arrival affects the coastal impact, especially if the target coast is exposed to significant tidal variations (Dao and Tkalich 2007; Omira et al. 2016). In the Atlantic Ocean, where our study area is located, the tide presents important variations and the peak-to-peak tidal amplitude can be as high as 4-5 $\mathrm{m}$. In this study, we account for the tidal variations in the region to evaluate the sensitivity of both impact and vulnerability to tsunami-tide interaction. To do so, we simulate the tsunami inundation, for each scenario, considering three static tidal stages, MLLW, MSL and MHHW. Then, tsunami vulnerability is evaluated within the inundation zones corresponding to the interaction of the tsunami with each one of the three tidal stages. Results depicting 
the influence of the tide level on the tsunami impact and vulnerability are summarized in Table 3 and Fig. 7, respectively.

Examination of the sensitivity analysis results (Table 3 and Fig. 7) clearly shows that both tsunami impact and vulnerability increase with the increase of tide amplitude. Larger MIE and MIA $\left(1.30 \mathrm{~km}\right.$ and $2.46 \mathrm{~km}^{2}$, respectively) were simulated for the aggregate scenario in MHHW condition that in MSL and MLLW conditions. Also, the building vulnerability shows, with respect to MSL stage, an increase of $8.40 \%$ and a decrease of $5.34 \%$ at MHHW and MLLW conditions (Fig. 7), respectively.

It is also worth pointing out here that this study suffers from some limitations related to the models used for the earthquake rupture, the tsunami simulations, the DEM construction, and the BTV assessment. In spite of all these limitations and simplifications, the result obtained in this paper contributes to develop a better understanding of tsunami hazard and vulnerability along the coast of Morocco.

\section{Conclusions}

In this study we investigate tsunami building vulnerability in a coastal area of the Atlantic Ocean, AsilahMorocco, where historical tsunami events are relatively well documented. A scenario-based approach and a qualitative GIS-based model were used to evaluate the levels of tsunami impact and building vulnerability of the Asilah coastal area. The main findings of this study are:

1. Tsunami impact calculated at Asilah supports the results of previous works suggesting that the Northwestern coast of Morocco is one of the tsunami hazardous coasts of the Atlantic Ocean;

2. A large percentage of the building stock within the inundation zone at Asilah (41.6\%) are highly vulnerable to tsunami impact suggesting that the structures are not designed to resist the tsunami impact.

3. The tidal variation along the Atlantic coast of Morocco affects the tsunami inundation and consequently the vulnerability of the building environment.

4. Buildings of the Old town, which present the historical and cultural patrimony of Asilah, should benefit from building restoration programs, since large part of this zone belongs to a high vulnerability level.

In summary, the results of this work have potential implications for risk and emergency management and long-term land-use zoning and development of building resistant design and construction standards.

\section{Acknowledgements}

This work is supported by the Moroccan Priority Research Project "ICANGETMAR" - Funded by the Ministry of Higher Education, Scientific Research and Executive Training, Morocco. Our gratitude is also addressed to the reviewers for their reviews, discussions, and suggestions on the manuscript.

\section{Funding}

"Not applicable"

\section{Availability of data and materials \\ "Not applicable"}

\section{Authors' contributions}

SEL performed the field research, collected and analyzed the data, and wrote the first draft of the manuscript. RO conceived of the study, performed the numerical modeling, data interpretation and revised the manuscript. MNZ participated in design and coordination of the study. HEL collected the data, went for field study and helped to interpret the results. KA revised the manuscript. All of the authors read and approved the final manuscript.

\section{Authors' information}

SEL, Ph.D. student at the Faculty of Sciences and Techniques of Tangier (Morocco), RO, Ph.D. in geophysics, researcher at IPMA (Portugal), and expert in natural hazards associated to tsunamis. MNZ full professor of geology at the Faculty of Sciences and Techniques of Tangier (Morocco). HEL, Ph.D. in Natural Hazards, associate professor at the Faculty of Sciences and Techniques of Al-Hoceima (Morocco). KA, full professor of geology at the Faculty of Sciences and Techniques of Tangier (Morocco).

\section{Competing interests}

All authors certify that there is no actual or potential significant competing financial, professional or personal interests that might have influenced the performance or presentation of the work described in this manuscript.

\section{Publisher's Note}

Springer Nature remains neutral with regard to jurisdictional claims in published maps and institutional affiliations.

\section{Author details}

${ }^{1}$ Faculty of Sciences and Techniques, University Abdelmalek Essaadi, Tangier, Morocco. ${ }^{2}$ Instituto Português do Mar e da Atmosfera, IPMA, I. P, Lisbon, Portugal. ${ }^{3}$ Instituto Dom Luiz, University of Lisbon, IDL, Lisbon, Portugal. ${ }^{4}$ Faculty of Sciences and Techniques, University Mohammed the first, Al Hoceima, Morocco.

Received: 30 October 2017 Accepted: 4 December 2017

Published online: 12 December 2017

\section{References}

Adger, W. Neil, Terry P. Hughes, Carl Folke, Stephen R. Carpenter, and Johan Rockström. 2005. Social-Ecological Resilience to Coastal Disasters. Science 309: 1036-1039. doi:10.1126/science.1112122.

Androsov, A., J. Behrens, and S. Danilov. 2010. Interaction between tides and tsunami waves. In Proc. of the Indian Ocean Tsunami Modelling Symposium, Fremantle.

Atillah, A., D. El Hadani, H. Moudni, O. Lesne, C. Renou, A. Mangin, and F. Rouffi. 2011. Tsunami vulnerability and damage assessment in the coastal area of Rabat and Salé Morocco. Natural Hazards and Earth System Sciences 11: 3397-3414. doi:10.5194/nhess-11-3397-2011.

Baptista, M.A., and J.M. Miranda. 2009. Revision of the Portuguese catalog of tsunamis. Natural Hazards and Earth System Sciences 9: 25-42. doi:10.5194/ nhess-9-25-2009.

Baptista, M.A., S. Heitor, J.M. Miranda, P. Miranda, and L. Mendes Victor. 1998. The 1755 Lisbon tsunami; evaluation of the tsunami parameters. Journal of Geodynamics 25: 143-157. doi:10.1016/50264-3707(97)00019-7.

Baptista, M.A., J.M. Miranda, R. Omira, and C. Antunes. 2011. Potential inundation of Lisbon downtown by a 1755-like tsunami. Natural Hazards and Earth System Sciences 11: 3319-3326. doi:10.5194/nhess-11-3319-2011.

Benchekroun, Sabah, Rachid Omira, Maria Ana Baptista, Azelarab El Mouraouah, Aomar Iben Brahim, and El Arbi Toto. 2015. Tsunami impact and vulnerability 
in the harbour area of tangier, Morocco. Geomatics, Natural Hazards and Risk 6: 718-740. doi:10.1080/19475705.2013.858373.

Blanc, Paul-Louis. 2008. The tsunami in Cadiz on 1 November 1755: A critical analysis of reports by Antonio de Ulloa and by Louis Godin. Comptes Rendus Geoscience 340: 251-261. doi:10.1016/j.crte.2007.12.001.

Blanc, Paul-Louis. 2009. Earthquakes and tsunami in November 1755 in Morocco: A different reading of contemporaneous documentary sources. Natural Hazards and Earth System Sciences 9: 725-738. doi:10.5194/nhess-9-725-2009.

Cherkaoui, Taj-Eddine, and Ahmed El Hassani. 2012. Seismicity and seismic hazard in Morocco. Bulletin de I'Institut Scientifique, Rabat, section Sciences de la Terre 34: 45-55.

Dao, M.H., and P. Tkalich. 2007. Tsunami propagation modelling - A sensitivity study. Natural Hazards and Earth System Sciences 7: 741-754. doi:10.5194/ nhess-7-741-2007

Dias, W.P.S., H.D. Yapa, and L.M.N. Peiris. 2009. Tsunami vulnerability functions from field surveys and Monte Carlo simulation. Civil Engineering and Environmental Systems 26: 181-194. doi:10.1080/10286600802435918.

Dominey-Howes, Dale, and Maria Papathoma. 2007. Validating a tsunami vulnerability assessment model (the PTVA model) using field data from the 2004 Indian Ocean tsunami. Natural Hazards 40: 113-136. doi:10.1007/ s11069-006-0007-9.

DPDPM. 2014. Annuaire des marées : Larache 2014. Enregistrement. Annuaire des marées. Rabat, Maroc: Direction des Ports et du Domaine Public Maritime, Ministère de l'Equipement et du Transport.

DPDPM. 2015. Annuaire des marées : Larache 2015. Enregistrement. Annuaire des marées. Rabat, Maroc: Direction des Ports et du Domaine Public Maritime, Ministère de l'Equipement et du Transport.

DPDRSP. 2004. Surveillance de la qualite des eaux des baignades de al zone atlantique du Nord du Maroc: Mai 2003-Fevrier 2004. Morocco: Direction of Ports and Direction of Risk Survey and Prevention.

El Alami, S.O., and Stefano Tinti. 1991. A preliminary evaluation of the tsunami hazards in the Moroccan coasts sc. Of tsunami hazards. Science of Tsunami Hazards 9: 31-38.

El Mrabet, Touria. 1991. La sismicité historique du Maroc. Thèse de 3e cycle, Rabat: Univ. Mohamed V, Fac. Lettres et Sciences Humaines.

El Mrabet, Touria. 2005. The great earthquakes in the Maghreb region and their consequences on man and environment: 270.

El Talibi, Hajar, Said El Moussaoui, Mohamed Najib Zaghloul, Khadija Aboumaria, Patrick Wassmer, and Jean Luc Mercier. 2016. New sedimentary and geomorphic evidence of tsunami flooding related to an older events along the tangier-Asilah coastal plain, Morocco. Geoenvironmental Disasters 3: 14. doi:10.1186/s40677-016-0049-6.

González, F.I., E.L. Geist, B. Jaffe, U. Kânoğlu, H. Mofjeld, C.E. Synolakis, V.V. Titov, et al. 2009. Probabilistic tsunami hazard assessment at seaside, Oregon, for near- and far-field seismic sources. Journal of Geophysical Research: Oceans 114: C11023. doi:10.1029/2008JC005132.

Gràcia, Eulàlia, Juanjo Dañobeitia, Jaume Vergés, and Parsifal Team. 2003. Mapping active faults offshore Portugal $\left(36^{\circ} \mathrm{N}-38^{\circ} \mathrm{N}\right)$ : Implications for seismic hazard assessment along the southwest Iberian margin. Geology 31: 83-86. doi:10.1130/0091-7613(2003)031<0083:MAFOPN>2.0.CO;2.

Gutscher, Marc-André. 2004. What caused the great Lisbon earthquake? Science 305: 1247-1248. doi:10.1126/science.1101351.

Gutscher, M.-A., J. Malod, J.-P. Rehault, I. Contrucci, F. Klingelhoefer, L. MendesVictor, and W. Spakman. 2002. Evidence for active subduction beneath Gibraltar. Geology 30: 1071-1074. doi:10.1130/0091-7613(2002)030<1071: EFASBG > 2.0.CO;2.

Gutscher, M.-A., M.A. Baptista, and J.M. Miranda. 2006. The Gibraltar arc seismogenic zone (part 2): Constraints on a shallow east dipping fault plane source for the 1755 Lisbon earthquake provided by tsunami modeling and seismic intensity. Tectonophysics 426. Natural laboratories on Seismogenic faults, 153-166. doi:10.1016/j.tecto.2006.02.025.

Johnston, Arch C. 1996. Seismic moment assessment of earthquakes in stable continental regions-I. Instrumental seismicity. Geophysical Journal International 124: 381-414. doi:10.1111/j.1365-246X.1996.tb07028.x.

Kaabouben, F., M.A. Baptista, A. Iben Brahim, A. El Mouraouah, and A. Toto. 2009. On the moroccan tsunami catalogue. Natural Hazards and Earth System Sciences 9: 1227-1236. doi:10.5194/nhess-9-1227-2009.

Kalmbacher, K.D., and D.F. Hill. 2015. Effects of tides and currents on tsunami propagation in large rivers: Columbia River, United States. Journal of Waterway, Port, Coastal, and Ocean Engineering 141: 04014046. doi:10.1061/ (ASCE)WW.1943-5460.0000290
Kowalik, Zygmunt, and Andrey Proshutinsky. 2010. Tsunami-tide interactions: A cook inlet case study. Continental shelf research 30. Tides in marginal seas - a special issue in memory of Prof Alexei Nekrasov, 633-642. doi:10. 1016/j.csr.2009.10.004.

Kowalik, Zygmunt, Tatiana Proshutinsky, and Andrey Proshutinsky. 2006. Tidetsunami interactions. Science of Tsunami Hazards 24: 242-256.

Leone, Frédéric, Franck Lavigne, Raphaël Paris, Jean-Charles Denain, and Freddy Vinet. 2011. A spatial analysis of the December 26th, 2004 tsunami-induced damages: Lessons learned for a better risk assessment integrating buildings vulnerability. Applied Geography 31. Hazards, 363-375. doi:10.1016/j.apgeog. 2010.07.009.

Liu, P LF., SB Woo, and YS Cho. 1998. Computer programs for tsunami propagation and inundation. Technical report. Cornell University.

Løvholt, F., H. Bungum, C.B. Harbitz, S. Glimsdal, C.D. Lindholm, and G. Pedersen. 2006. Earthquake related tsunami hazard along the western coast of Thailand. Natural Hazards and Earth System Sciences 6: 979-997. doi:10.5194/ nhess-6-979-2006.

Martínez Solares, J.M., and A. López Arroyo. 2004. The great historical 1755 earthquake effects and damage in Spain. Journal of Seismology 8: 275-294. doi:10.1023/B:JOSE.0000021365.94606.03.

Martínez Solares, J.M., A. Lopez Arroyo, and J. Mezcua. 1979. Isoseismal map of the 1755 Lisbon earthquake obtained from Spanish data. Tectonophysics 53. Proceedings of the 16th general assemble of the European seismological commission, 301-313. doi:10.1016/0040-1951(79)90075-1.

Matias, L., A. Ribeiro, M.A. Baptista, N. Zitellini, J. Cabral, P. Terrinha, P. Teves-Costa, and J.M. Miranda. 2005. Comment on "Lisbon 1755: A case of triggered onshore rupture?" by Susana P. Vilanova, Catarina F. Nunes, and Joao F. B. D. Fonseca. Bulletin of the Seismological Society of America 95: 2534-2538. doi:10. 1785/0120040023.

Matias, L.M., T. Cunha, A. Annunziato, M.A. Baptista, and F. Carrilho. 2013. Tsunamigenic earthquakes in the Gulf of Cadiz: Fault model and recurrence. Natural Hazards and Earth System Sciences 13: 1-13. doi:10. 5194/nhess-13-1-2013.

Medina, F., N. Mhammdi, A. Chiguer, M. Akil, and E.B. Jaaidi. 2011. The Rabat and Larache boulder fields; new examples of high-energy deposits related to storms and tsunami waves in north-western Morocco. Natural Hazards 59: 725. doi:10.1007/s11069-011-9792-x.

Mhammdi, Nadia, Fida Medina, Dieter Kelletat, M'Fedal Ahmamou, and Lamiaa Aloussi. 2008. Large boulders along the Rabat coast (Morocco); possible emplacement by the November, 1st, 1755 a.D. tsunami. Science of tsunami hazards.

Miller, G.R., W.H. Munk, and F.E. Snodgrass. 1962. Long-period waves over California's continental borderland, II, tsunamis. Journal of Marine Research 20: 31-41.

Mofjeld, Harold O., Frank I. GonzáLez, Eddie N. Bernard, and Jean C. Newman. 2000. Forecasting the heights of later waves in Pacific-wide tsunamis. Natural Hazards 22: 71-89. doi:10.1023/A:1008198901542.

Mofjeld, Harold O., Frank I. González, Vasily V. Titov, Angie J. Venturato, and Jean C. Newman. 2007. Effects of tides on maximum tsunami Wave Heights: Probability distributions. Journal of Atmospheric and Oceanic Technology 24: 117-123. doi:10.1175/JTECH1955.1.

Omira, R., M.A. Baptista, L. Matias, J.M. Miranda, C. Catita, F. Carrilho, and E. Toto. 2009. Design of a sea-Level Tsunami Detection Network for the Gulf of Cadiz. Natural Hazards and Earth System Sciences 9: 1327-1338. doi:10.5194/nhess-9-1327-2009.

Omira, R., M.A. Baptista, J.M. Miranda, E. Toto, C. Catita, and J. Catalão. 2010. Tsunami vulnerability assessment of Casablanca-Morocco using numerical modelling and GIS tools. Natural Hazards 54: 75-95. doi:10.1007/s11069009-9454-4.

Omira, R., M.A. Baptista, and J.M. Miranda. 2011. Evaluating tsunami impact on the Gulf of Cadiz coast (Northeast Atlantic). Pure and Applied Geophysics 168: 1033-1043. doi:10.1007/s00024-010-0217-7.

Omira, R., M.A. Baptista, S. Mellas, F. Leone, N. Meschinet de Richemond, B. Zourarah, and J.-P. Cherel. 2012. The November, 1st, 1755 tsunami in Morocco: Can numerical modeling clarify the uncertainties of historical reports? doi:10. 5772/51864.

Omira, R., M.A. Baptista, F. Leone, L. Matias, S. Mellas, B. Zourarah, J.M. Miranda, F. Carrilho, and J.-P. Cherel. 2013. Performance of coastal sea-defense infrastructure at el Jadida (Morocco) against tsunami threat: Lessons learned from the Japanese 11 march 2011 tsunami. Natural Hazards and Earth System Sciences 13: 1779-1794. doi:10.5194/nhess-13-1779-2013. 
Omira, R., L. Matias, and M.A. Baptista. 2016. Developing an event-tree probabilistic tsunami inundation model for NE Atlantic coasts: Application to a case study. Pure and Applied Geophysics 173: 3775-3794. doi:10.1007/ s00024-016-1367-z.

Papathoma, M., D. Dominey-Howes, Y. Zong, and D. Smith. 2003. Assessing tsunami vulnerability, an example from Herakleio. Crete. Nat. Hazards Earth Syst. Sci. 3: 377-389. doi:10.5194/nhess-3-377-2003.

Post, J., S. Wegscheider, M. Mück, K. Zosseder, R. Kiefl, T. Steinmetz, and G. Strunz. 2009. Assessment of human immediate response capability related to tsunami threats in Indonesia at a sub-national scale. Natural Hazards and Earth System Sciences 9: 1075-1086. doi:10.5194/nhess-9-1075-2009.

Reese, S., W.J. Cousins, W.L. Power, N.G. Palmer, I.G. Tejakusuma, and S. Nugrahadi. 2007. Tsunami vulnerability of buildings and people in south java - Field observations after the July 2006 java tsunami. Natural Hazards and Earth System Sciences 7: 573-589. doi:10.5194/nhess-7-573-2007.

Renou, C., O. Lesne, A. Mangin, F. Rouffi, A. Atillah, D. El Hadani, and H. Moudni. 2011. Tsunami hazard assessment in the coastal area of Rabat and Salé. Morocco. Nat. Hazards Earth Syst. Sci. 11: 2181-2191. doi:10. 5194/nhess-11-2181-2011.

RGPH. 2014. Recensement General de la Population et de l'Habitat 2014 : Caracteristiques démographiques et socio-économiques, Prefecture de Tanger-Assilah. Serie Provinciale. Tanger: Haut-Commissariat au Plan, Direction Régionale de Tanger Tétouan Al Hoceima.

Soyris, Mr. 1755. Extrait d'une lettre de Maroc en date du 5 novembre 1755: de Soyris a Guys. Archives Nationales de France. Marine B7/403. Archives Nationales de France,

Suppasri, Anawat, Erick Mas, Shunichi Koshimura, Kentaro Imai, Kenji Harada, and Fumihiko Imamura. 2012. Developing tsunami fragility curves from the surveyed data of the 2011 great east japan tsunami in sendai and ishinomaki plains. Coastal Engineering Journal 54: 1250008. doi:10.1142/ S0578563412500088.

Suppasri, Anawat, Erick Mas, Ingrid Charvet, Rashmin Gunasekera, Kentaro Imai, Yo Fukutani, Yoshi Abe, and Fumihiko Imamura. 2013. Building damage characteristics based on surveyed data and fragility curves of the 2011 great East Japan tsunami. Natural Hazards 66: 319-341. doi:10. 1007/s11069-012-0487-8

Tinti, Stefano, and Alberto Armigliato. 2003. The use of scenarios to evaluate the tsunami impact in southern Italy. Marine Geology 199: 221-243. doi:10.1016/ S0025-3227(03)00192-0.

Tinti, Stefano, Alberto Armigliato, Gianluca Pagnoni, and Filippo Zaniboni. 2005. Scenarios of giant tsunamis of tectonic origin in the mediterranean. ISET Journal of Earthquake Technology 42: 171-188.

Tinti, Stefano, Roberto Tonini, Lidia Bressan, Alberto Armigliato, Annalisa Gardi, Richard Guillande, Nathalia Valencia, and Stefan Scheer. 2011. Handbook on tsunami hazards and damage scenarios. EUR - scientific and technical research reports. Publications Office of the European Union, JRC61463.

Valencia, N., A. Gardi, A. Gauraz, F. Leone, and R. Guillande. 2011. New tsunami damage functions developed in the framework of SCHEMA project: Application to European-Mediterranean coasts. Natural Hazards and Earth System Sciences 11: 2835-2846. doi:10.5194/nhess-11-2835-2011.

Van Dorn, W.G. 1984. Some tsunami characteristics deducible from tide records. Journal of Physical Oceanography 14: 353-363. doi:10.1175/15200485(1984)014<0353:STCDFT>2.0.CO;2.

Van Dorn, W.G. 1987. Tide Gage Response to Tsunamis. Part II: Other Oceans and Smaller Seas. Journal of Physical Oceanography 17: 1507-1516. doi:10.1175/ 1520-0485(1987)017<1507:TGRTTP>2.0.CO;2.

Wang, Xiaoming. 2009. COMCOT user manual-version 1.7. School of Civil and Environmental Engineering, Cornell University Ithaca. New York, USA: School of Civil and Environmental Engineering, Cornell University Ithaca. School of Civil and Environmental Engineering, Cornell University Ithaca.

Wang, Xiaoming, and Philip L.-F. Liu. 2005. A numerical investigation of Boumerdes-Zemmouri (Algeria) earthquake and tsunami. CMES: Computer Modeling in Engineering \& Sciences 10: 171-184. doi:10.3970/ cmes.2005.010.171.

Wang, Xiaoming, and Philip L.-F. Liu. 2006. An analysis of 2004 Sumatra earthquake fault plane mechanisms and Indian Ocean tsunami. Journal of Hydraulic Research 44: 147-154. doi:10.1080/00221686.2006.9521671.

Weisz, R., and C. Winter. 2005. Tsunami, tides and run-up: A numerical study. In proceedings of the international tsunami symposium, edited by: Papadopoulos. GA and Satake, K., Chania, Greece 322: 27-29.
Wronna, M., R. Omira, and M.A. Baptista. 2015. Deterministic approach for multiple-source tsunami hazard assessment for Sines Portugal. Natural Hazards and Earth System Sciences 15: 2557-2568. doi:10.5194/nhess-152557-2015.

Zitellini, N., F. Chierici, R. Sartori, and L. Torelli. 1999. The tectonic source of the 1755 Lisbon earthquake and tsunami. Annals of Geophysics 42. doi: 10.4401/ag-3699.

Zitellini, Nevio, L.A. Mendes, D. Cordoba, J. Danobeitia, R. Nicolich, G. Pellis, A. Ribeiro, et al. 2001. Source of 1755 Lisbon earthquake and tsunami investigated. Eos, Transactions American Geophysical Union 82: 285-291. doi: 10.1029/EO082i026p00285-01.

\section{Submit your manuscript to a SpringerOpen ${ }^{\circ}$ journal and benefit from:}

- Convenient online submission

- Rigorous peer review

- Open access: articles freely available online

- High visibility within the field

- Retaining the copyright to your article

Submit your next manuscript at springeropen.com 